\title{
Emerging risk factors for nonalcoholic fatty liver disease associated hepatocellular carcinoma
}

\author{
Jihane N. Benhammou' ${ }^{1}$, Jonathan Lin², Shehnaz K. Hussain ${ }^{3,4}$, Mohamed El-Kabany ${ }^{1}$ \\ 'Pfleger Liver Institute, University of California Los Angeles, Los Angeles, CA 90095, USA. \\ ${ }^{2}$ Vatche and Tamar Manoukian Division of Digestive Diseases, David Geffen School of Medicine at UCLA, Los Angeles, CA \\ 90095, USA. \\ ${ }^{3}$ Department of Epidemiology, Fielding School of Public Health, University of California, CA 90095, USA. \\ ${ }^{4}$ Department of Medicine, Samuel Oschin Comprehensive Cancer Institute, Cedars-Sinai Medical Center, Los Angeles, CA \\ 90048 , USA.
}

Correspondence to: Dr. Mohamed El-Kabany, Pfleger Liver Institute, 200 Medical Plaza, Los Angeles, CA 90095, USA.

E-mail: melkabany@mednet.ucla.edu

How to cite this article: Benhammou JN, Lin J, Hussain SK, El-Kabany M. Emerging risk factors for nonalcoholic fatty liver disease associated hepatocellular carcinoma. Hepatoma Res 2020;6:35. http://dx.doi.org/10.20517/2394-5079.2020.16

Received: 24 Feb 2020 First Decision: 24 Apr 2020 Revised: 6 May 2020 Accepted: 13 May 2020 Published: 18 Jun 2020

Science Editor: Guido Guenther Gerken Copy Editor: Jing-Wen Zhang Production Editor: Tian Zhang

\begin{abstract}
Worldwide, nonalcoholic fatty liver disease (NAFLD) has reached epidemic proportions and in parallel, hepatocellular carcinoma (HCC) has become one of the fastest growing cancers. Epidemiological studies have not only shed light on the prevalence and incidence of the disease but have also unmasked important environmental risk factors, including the role of diabetes and dyslipidemia in disease pathogenesis. Genetic association studies have identified single nucleotide polymorphisms implicated in NAFLD-HCC, many of which are part of lipid metabolism pathways. Through these clinical studies and subsequently, translational and basic research, the role of statins as a chemoprotective agent has also emerged with ongoing clinical trials assessing their utility in HCC prevention and treatment. In this review, we summarize the recent epidemiological studies describing the burden of NAFLD-HCC in different patient populations and countries. We discuss the genetic and environmental risk factors for NAFLD-HCC and highlight the chemoprotective role of statins and aspirin. We also summarize what is known about NAFLD-HCC in the cirrhosis and non-cirrhosis populations and briefly address the role of surveillance in NAFLD-HCC patients.
\end{abstract}

Keywords: Nonalcoholic fatty liver disease, nonalcoholic steatohepatitis, hepatocellular carcinoma, statins, metabolic syndrome

\section{INTRODUCTION}

The metabolic syndrome (MetS), defined by the clustering of biochemical and clinical features, which includes type 2 diabetes (T2D), hypertension, dyslipidemia and obesity, has reached epidemic proportions ${ }^{[1]}$.

cc) (7) The Author(s) 2020. Open Access This article is licensed under a Creative Commons Attribution 4.0 International License (https://creativecommons.org/licenses/by/4.0/), which permits unrestricted use sharing, adaptation, distribution and reproduction in any medium or format, for any purpose, even commercially, as long as you give appropriate credit to the original author(s) and the source, provide a link to the Creative Commons license, and indicate if changes were made. 
Table 1. NAFLD-associated HCC epidemiology and burden

\begin{tabular}{|c|c|c|c|c|}
\hline Country & Incidence and prevalence & Population & Study period & Ref. \\
\hline United States & $\begin{array}{l}0.21 \text { per } 1000 \text { person-years } \\
14.1 \% \text { of all cases } \\
8 \% \text { of all HCC cases } \\
1.56 \% \text { of HCC cases } \\
5.29 \text { per } 1000 \text { person-years } \\
13.5 \% \text { of all liver transplants }\end{array}$ & $\begin{array}{l}\text { Veterans Affairs } \\
\text { SEER registries } \\
\text { Veterans Affairs } \\
\text { Veterans Affairs } \\
\text { Meta-analysis } \\
\text { United Network Organ for Sharing }\end{array}$ & $\begin{array}{l}2003-2011 \\
2004-2009 \\
2005-2011 \\
2012-2018 \\
1989-2015 \\
2000-2012\end{array}$ & $\begin{array}{l}\text { Kanwal et al. }{ }^{[22]} \\
\text { Younossi et al. }{ }^{[136]} \\
\text { Mittal et al. }{ }^{[23]} \\
\text { loannou et al. }{ }^{[24]} \\
\text { Younossi et al. }{ }^{[3]} \\
\text { Wong et al. }{ }^{[26]}\end{array}$ \\
\hline $\begin{array}{l}\text { Spain, Italy, the Netherlands, United Kingdom } \\
\text { United Kingdom }\end{array}$ & $\begin{array}{l}0.3 \text { per } 1000 \text { person-years } \\
35 \% \text { of all HCC referrals }\end{array}$ & $\begin{array}{l}\text { European primary care databases } \\
\text { National Health Services }\end{array}$ & $\begin{array}{l}2016 \\
2010\end{array}$ & $\begin{array}{l}\text { Alexander et al. } \\
\text { Dyson et al. }\end{array}$ \\
\hline $\begin{array}{l}\text { Japan } \\
\text { South Korea }\end{array}$ & $\begin{array}{l}6 \% \text { incidence } \\
12.2 \% \text { incidence }\end{array}$ & $\begin{array}{l}\text { Single hospital in Tokyo } \\
\text { South Korean hospital }\end{array}$ & $\begin{array}{l}1994-2007 \\
2006-2010\end{array}$ & $\begin{array}{l}\text { Arase et }\left.a\right|_{.} ^{[138]} \\
\text { Cho et al. }{ }^{[34]}\end{array}$ \\
\hline
\end{tabular}

NAFLD: nonalcoholic fatty liver disease; HCC: hepatocellular carcinoma; SEER: surveillance, epidemiology and end results

Non-alcoholic fatty liver disease (NAFLD), the liver manifestation of MetS, has increased in parallel and is now the most common cause of liver disease in the United States ${ }^{[2]}$. Although the true prevalence of NAFLD remains unknown given the lack of validated and/or recommended screening practices, it is estimated that the disease affects about a quarter of the world's population, depending on geographical differences ${ }^{[3]}$. NAFLD can progress to nonalcoholic steatohepatitis (NASH) ${ }^{[3]}$ (characterized by $\geq 5 \%$ of hepatic steatosis with lobular inflammation and hepatocyte ballooning ${ }^{[4]}$ ), cirrhosis and hepatocellular carcinoma $(\mathrm{HCC})^{[5,6]}$. Given the estimated increase in NAFLD, NASH and NAFLD-associated HCC ${ }^{[7]}$ and the anticipated burden on health care $\operatorname{costs}^{[8-10]}$, several studies have focused on understanding the clinical and biological drivers of NAFLD-associated HCC and its potential treatment options.

Understanding this disease process is especially relevant since NAFLD-associated HCC can occur in a noncirrhotic background ${ }^{[11-13]}$. This poses a clinical dilemma given the lack of screening guidelines for this subgroup of patients, thus prompting the need for further understanding of the natural history of NAFLDHCC and identifying at-risk populations who would benefit from screening. More recently, studies have also identified the protective effects of statins and aspirin on fibrosis progression and $\mathrm{HCC}^{[14-17]}$, providing an avenue for further research in this group of patients who are also at high risk for cardiovascular disease.

A full review and discussion of the pathophysiology of NAFLD and NASH is beyond the scope of this report and has been summarized by Anstee et al ${ }^{[18]}$. In this review, we explore what is known about the genetic (non-modifiable) and environmental (modifiable) risk factors of NAFLD-associated HCC, examine the role of statins and aspirin and what microbiome research has to offer in the field of NAFLD-related HCC.

\section{BURDEN OF NAFLD-ASSOCIATED HCC}

HCC is a lethal cancer with a rising incidence over the last 30 years $^{[19]}$. Its incidence is increasing most rapidly of any cancer, with an age-adjusted annual increase of $3.8 \%$ and $2.8 \%$ in men and women in the U.S., respectively $^{[20]}$. The rising HCC burden has largely been attributed to the rise in obesity and diabetes ${ }^{[21]}$. As follows, several epidemiological studies have specifically examined the incidence and risk of NAFLDassociated HCC [Table 1]. The results have been varied however, due to differences between the studies in patient population, time-period, and NAFLD and/or NASH ascertainment. For example, in a large Veterans Affairs (VA) Health System study between 2003-2011, the incidence of HCC in a NAFLD cohort was 0.21 per 1000 person-years ${ }^{[22]}$. A separate study within the VA further demonstrated that of the 1500 HCC cases identified from 2005-2011, NAFLD was the underlying risk factor in $8 \%$ of all cases with an annual proportion of NAFLD-related HCC ranging from 7.5\%-12.0\% ${ }^{[23]}$. Ioannou et al.$^{[24]}$ also reported that the incidence of NAFLD-associated HCC was 1.56\% within the VA from 2012-2018 over a 3.7 years follow up period. In non-VA populations, the incidence rate for NAFLD-associated HCC and NASH-associated HCC were 0.44 and 5.29 per 1000 person-years, respectively ${ }^{[3]}$.

Changes in liver transplantation (LT) indications are also reflective of the increasing rates of NAFLD. For instance, Younossi et al. ${ }^{[25]}$ demonstrated that of 158,347 LT candidates from 2002-2016, the prevalence of 
NAFLD-associated HCC increased by 11.8 fold, which was higher than hepatitis B, hepatitis C and alcoholic liver disease. Other studies have also corroborated that NAFLD and NAFLD-associated HCC are the most rapidly growing indications for $\mathrm{LT}^{[26,27]}$.

Other countries in Europe and Asia have made similar observations to these U.S.-based studies ${ }^{[28,29]}$. In a European Electronic Health Record study of patients seen in primary care in Spain, Italy, the Netherlands and the United Kingdom, the incidence of NAFLD-associated HCC diagnosis was 0.3 per 1000 person-years over a median follow up of 3.3 years $^{[30]}$. A study of the European Liver Transplant Registry database from 2002-2016 also showed that among the 68,950 transplant patients, 8.4\% were for NASH in 2016 (compared to $1.3 \%$ in 2002 ), $39 \%$ of whom had $\mathrm{HCC}^{[31]}$. In Asian countries, where hepatitis B has been the main driver of liver disease and HCC, the prevalence of NAFLD is also about $25 \%$ depending on the country studied, ranging from $6.2 \%$ in South China to $51 \%$ in Indonesia ${ }^{[3,32,33]}$. NAFLD-associated HCC has also increased in countries such as South Korea where its prevalence rose from 3.8\% (2001-2005) to 12.2\% (2006-2010) ${ }^{[34]}$.

Although a rise in sedentary life styles leading to increase in MetS and diabetes are thought to be the culprits in NAFLD-associated HCC, Asian patients are more likely to have "lean" or "non-obese" NAFLD, potentially representing a pathophysiolocally different group of patients from those seen in Western countries. Few studies have addressed this although a recent European study assessing the outcomes of biopsy-proven lean NAFLD (BMI $\left.<25 \mathrm{~kg} / \mathrm{cm}^{2} ; n=123\right)$ patients compared to healthy controls, overweight NAFLD $\left(\right.$ BMI $\left.25-30 \mathrm{~kg} / \mathrm{cm}^{2} ; n=335\right)$ and obese NAFLD patients (BMI $\left.>30 \mathrm{~kg} / \mathrm{cm}^{2} ; n=188\right)$ demonstrated that lean NAFLD patients had a tendency towards more liver-related complications including cirrhosis, decompensated cirrhosis and HCC over a follow-up period of 19.9 years ${ }^{[35]}$.

In summary, the burden of NAFLD-HCC is on the rise with the prevalence of NAFLD, depending on geographical and ethnic differences, affecting about a quarter of the world's population. Although NASH is thought to be a more severe form of NAFLD that more commonly progresses to chronic liver disease and HCC, the true prevalence of NAFLD (6.2\%-51\%) and NASH (10\%-20\%), based on large epidemiological data, remains unclear given that no specific biomarkers exist to differentiate the two other than a liver biopsy, which is scarcely performed, yet the gold standard for diagnosis.

\section{GENETIC RISK FACTORS FOR NAFLD-HCC}

There is a large body of literature linking genetic polymorphisms to the development of NAFLD and NASH but few have addressed the genetic contributions to NAFLD-associated HCC [Table 2]. Early studies in the field of NAFLD identified ethnic differences in disease prevalence whereby Hispanics were the most commonly affected group followed by Caucasians and African Americans ${ }^{[36-38]}$, suggesting a genetic predisposition to NAFLD. Consistent with these findings, twin studies and phenotypic clustering of fatty liver were also more commonly seen in patients in the same family, suggesting heritability of the disease, which has been reported to range from $38 \%-50 \%$, depending on the modality used for phenotyping of NAFLD (biopsy, MRI or abdominal ultrasound) ${ }^{[39,40]}$. In recent years, large genome-wide studies have followed and revolutionized what is known about NAFLD and NASH, and possibly the risk for HCC development.

Romeo et al. ${ }^{[41]}$ conducted the first genome-wide association study in the Dallas Heart Study using proton magnetic resonance spectroscopy to quantitate hepatic steatosis as the phenotype. Patatin-like phospholipase domain 3, PNPLA3 (rs738409), was the single variant strongly associated with hepatic steatosis. Although the mechanism by which PNPLA3 leads to hepatic steatosis accumulation remains unknown, it was shown to play a role in hepatocellular lipid droplet remodeling and very low-density lipoprotein secretion ${ }^{[42,43]}$. Interestingly, subsequent association studies of PNPLA3 also demonstrated that the variant was associated with histological severity of the disease, thus suggesting that it may influence HCC development, where GG sequence carriers had more necroinflammation and fibrosis compared to CC carriers ${ }^{[44]}$. Indeed, Liu et al ${ }^{[45]}$, 
Table 2. Summary of NAFLD HCC polymorphisms

\begin{tabular}{|c|c|c|c|c|c|}
\hline SNP & Clinical significance & $\begin{array}{c}\text { Location (human } \\
\text { chromosome) }\end{array}$ & Associated gene & Role of the gene & Ref. \\
\hline $\begin{array}{l}r s 738409 \\
C>G\end{array}$ & $\begin{array}{l}\text { Associated with increased liver } \\
\text { fat accumulation and a higher } \\
\text { risk for developing liver cirrhosis. } \\
\text { Given the increased severity of } \\
\text { necroinflammation in GG sequence } \\
\text { carriers, these individuals may be at } \\
\text { higher risk for developing HCC }\end{array}$ & $\begin{array}{l}\text { chr22:43928847 } \\
\text { (GRCh38.p12) }\end{array}$ & $\begin{array}{l}\text { PNPLA3; Patatin- } \\
\text { like phospholipase } \\
\text { domain-containing } \\
\text { protein } 3\end{array}$ & $\begin{array}{l}\text { The PNPLA3 gene encodes } \\
\text { the protein Adiponutrin, } \\
\text { which is thought to help } \\
\text { regulate the development } \\
\text { of adipocytes as well as } \\
\text { lipogenesis and lipolysis in } \\
\text { the liver }\end{array}$ & $\begin{array}{l}\text { Sookoian et al. }{ }^{[44]} \\
\text { Shen et al. }\end{array}$ \\
\hline $\begin{array}{l}\text { rs58542926 } \\
C>T\end{array}$ & $\begin{array}{l}\text { Associated with an increased risk } \\
\text { of developing diabetes and NAFLD. } \\
\text { The polymorphism results in a loss } \\
\text { of function and individuals with } \\
\text { the CT phenotype have a reduced } \\
\text { hepatic capability to secrete LDLs } \\
\text { and are at higher risk for developing } \\
\text { liver inflammation and potentially } \\
\text { HCC }\end{array}$ & $\begin{array}{l}\text { chr19:19268740 } \\
\text { (GRCh38.p12) }\end{array}$ & $\begin{array}{l}\text { TM6SF2; } \\
\text { Transmembrane } 6 \\
\text { Superfamily Member } \\
2\end{array}$ & $\begin{array}{l}\text { The TM6SF2 gene is } \\
\text { involved in regulating liver } \\
\text { fat metabolism, lipoprotein } \\
\text { secretion and hepatic lipid } \\
\text { droplet content }\end{array}$ & $\begin{array}{l}\text { Kozlitina et } a{ }^{\left[.^{[46]}\right.} \\
\text { Falleti et al. }{ }^{[47]} \\
\text { Vespasiani- } \\
\text { Gentilucci et al. }{ }^{[140]}\end{array}$ \\
\hline $\begin{array}{l}\text { rs641738 } \\
C>T\end{array}$ & $\begin{array}{l}\text { Associated with an increased risk of } \\
\text { hepatic fat accumulation, fibrosis, } \\
\text { and potentially HCC }\end{array}$ & $\begin{array}{l}\text { chr19:54173068 } \\
\text { (GRCh38.p12) }\end{array}$ & $\begin{array}{l}\text { MBOAT7; } \\
\text { Membrane Bound } \\
\text { O-Acyltransferase } \\
\text { Domain Containing } 7\end{array}$ & $\begin{array}{l}\text { The MBOAT7 gene } \\
\text { encodes a protein known } \\
\text { as Lysophospholipid } \\
\text { acyltransferase } 7 \text { that is } \\
\text { involved in the re-acylation } \\
\text { of phospholipids as part of } \\
\text { the phospholipid remodeling } \\
\text { pathway }\end{array}$ & $\begin{array}{l}\text { Mancina et al. }{ }^{[48]} \\
\text { Luukkonen et al. }{ }^{[49]} \\
\text { Donati et al. }{ }^{[50]}\end{array}$ \\
\hline
\end{tabular}

NAFLD: nonalcoholic fatty liver disease; HCC: hepatocellular carcinoma; LDLs: low density lipoproteins

demonstrated that in a Northern European Caucasian cohort of patients with primary HCC attributed to NAFLD, carriage of the PNPLA3 rs738409 polymorphism was associated with NAFLD fibrosis and HCC, where GG carriers had a 5-fold increase in HCC (95\%CI: 1.47-17.29) compared to CC carriers.

In subsequent studies, the transmembrane 6 superfamily member 2, TM6SF2 (rs58542926), followed suit and was identified in an exome-wide association study of fatty liver and serum aminotransferases ${ }^{[46]}$. Although the association of TM6SF2 with NAFLD is well established, its association with HCC development is disputed ${ }^{[45,47]}$. More recently, the MBOAT7 (Membrane Bound O-Acetyltransferase Domain Containing 7) variant rs641738 has also been associated with NAFLD and its histological severity ${ }^{[48,49]}$. An Italian study of 132 NAFLD-associated HCC cases also linked the MBOAT4 variant to non-cirrhosis NAFLD HCC ${ }^{[50]}$. In another European study, Pelusi et al..$^{[51]}$ identified rare variants of candidate genes (SMAD4, SQSTM1, TEL, $R B 1$, TSC1), including APOB (Apolipoprotein B) which is involved in very low-density lipoprotein secretion and therefore export of lipids using whole exome sequencing methods. Noteworthy of these findings is the common thread of lipid metabolism genes being identified in genetic NAFLD and NAFLD-related HCC association studies. Although intrahepatic steatosis alone was thought to be benign and the hallmark of NAFLD, lipid dysregulation may play an important role in promoting carcinogenesis independently of NAFLD disease pathogenesis.

In addition to being at risk for NAFLD and NASH, Hispanic patients have been shown to be at risk of NAFLD-associated $\mathrm{HCC}^{[22,52,53]}$, which has been attributed largely to an increase in the incidence of cirrhosis $^{[22]}$. Similar to what has been reported in the literature, we found in our local cohort of 125 NAFLDassociated HCC cases, of whom $>85 \%$ had histological data available for review, that of the $20 \%$ of patients who did not have underlying cirrhosis or advanced fibrosis, none were of Hispanic background. However, the remaining cohort that had NAFLD-associated HCC cases in cirrhotic livers was Hispanic (manuscript submitted). Our findings and that of others suggest that although there are genetic predispositions to NAFLD and NASH, NAFLD-associated HCC may have independent mechanisms other than those at play for NAFLD disease progression and fibrosis. Further studies that are more inclusive of patients of non-European descent are needed to determine if these associations remain true in other populations. 
Beyond germ-like mutations that may predispose to disease, which has largely been the focus of genetic studies in NAFLD, heritable epigenetic changes also have an important role in NAFLD-associated HCC which include but are not limited to DNA methylation, chromosomal looping interactions, RNA modifications and the emerging role of non-coding RNAs ${ }^{[54-57]}$. Additionally, several studies have applied circulating tumor DNA (cfDNA) methods to further study HCC $^{[58,59]}$, which has not only shed some light on the biology of HCC but is also promising for use as a biomarker in the future. The identification of these epigenetic modifications points to further understanding of gene regulation changes, which are influenced by their environment ${ }^{[54]}$.

\section{NON-GENETIC ENVIRONMENTAL FACTORS FOR NAFLD-HCC: CLINICAL, PHARMACOLOGICAL AND LIFESTYLE FACTORS}

\section{Diabetes}

NAFLD is a complex trait with common and rare variants ${ }^{[51]}$ that are influenced by the environment. Clinical studies have demonstrated that the features of MetS affect NAFLD-associated HCC development. T2D has been known to affect the risk of HCC as early as when NAFLD and NASH were starting to become more recognized. The seminal VA study by El-Serag et al. ${ }^{[60]}$ demonstrated in a cohort of 173,643 Veterans followed for 10 years that T2D significantly increased the risk of HCC. Studies that followed not only corroborated these findings ${ }^{[61,62]}$ but also demonstrated an increase in the risk of HCC when more features of MetS were present ${ }^{[63]}$. Using a prospectively collected cohort in the Nurses' Health Study and Health Professionals' Health Study, Simon et al. ${ }^{[63]}$ found that the adjusted hazard ratio (HR) for HCC in patients with diabetes was 5.8 (95\%CI: 3.49-9.64) and 5.49 (95\%CI: 3.16-9.51) compared to non-diabetic patients in women and men after adjusting for baseline characteristics, respectively. Interestingly, the risk of HCC was also dependent on the duration of diabetes, solidifying the effects of T2D and insulin resistance on hepatocellular carcinogenesis. Compared to patients without diabetes, diabetic patients had an adjusted HR of 7.52 (95\%CI: 3.88-14.6) if they have had the disease for 10 years or more.

\section{Obesity}

Obesity has been associated with an increased risk of developing many cancers and this association is strongest for $\mathrm{HCC}^{[64,65]}$. By convention, BMI has been used to measure obesity in epidemiological studies. Although readily available in the clinical setting, BMI does not inform adipose distribution, specifically visceral versus peripheral, which have different implications on metabolic health. Early studies in patients with cirrhosis demonstrated that those with visceral adiposity were at higher risk of death compared to those with peripheral adipose tissue. Ioannou et al. ${ }^{[66]}$ elegantly demonstrated these associations using the National Health and Nutritional Examination Survey where patients were categorized based on central or peripheral adipose distribution. Among patients with central adipose distribution, cirrhosis-related death and hospitalizations were more common in the obese group (BMI $\geq 30 \mathrm{~kg} / \mathrm{m}^{2}$ ) (adjusted $\mathrm{HR}=2.2,95 \% \mathrm{CI}$ : 1.1-4.6) compared to normal-weight individuals $\left(\mathrm{BMI}<25 \mathrm{~kg} / \mathrm{m}^{2}\right)$, which was not observed in patients with increased peripheral adipose distribution. In NAFLD and NAFLD-associated HCC, central obesity, a key feature of MetS, is also more physiologically informative of metabolic health ${ }^{[67,68]}$. This is also relevant in the setting of studying NAFLD in groups of patients that may not have similar body compositions such as the Asian population, which tends to have a higher percentage of body fat compared to White patients ${ }^{[69]}$.

\section{Hypertension and dyslipidemia}

The evidence for hypertension, which is included in many definitions of MetS, is inconsistent and has been shown to be a risk factor in some studies but not others ${ }^{[7,71]}$. Many studies also use collective features of MetS to assess the attendant risk. Thus, the true effects of hypertension in isolation without other features of MetS are unclear. Similarly, the data on dyslipidemia is conflicting. For instance, Welzel et al. ${ }^{[70]}$ demonstrated that patients with a diagnosis of dyslipidemia based on ICDs demonstrated an adjusted odds ratio (OR) of 1.35 (95\%CI: 1.26-1.45) for NAFLD-HCC development, similar to others ${ }^{[63]}$. Other studies have shown 
the opposite effect however, in which a diagnosis of dyslipidemia was protective against $\mathrm{HCC}^{[72]}$. One potential reason for these conflicting reports is the definitions used to identify patients (i.e. ICDs versus lipid measurements versus medication use). These data must be interpreted in the context of statin use, which has more recently been shown to have chemoprotective effects against fibrosis progression and HCC ${ }^{[14,15]}$.

\section{Statins}

Early animal studies showed that statins, which inhibit the 3-hydroxy-3-methylglutaryl coenzyme A reductase (HMG-CoA reductase), cause hepatotoxicy. The level of hepatic injury did not translate to humans clinical trials however, and mostly caused asymptomatic abnormal aminotransferases that would resolve with time $^{[73]}$. Over the years, research and subsequently clinical practice has changed to favor the use of statins in NAFLD and NASH patients for the cardiovascular protective effects, which are closely linked to NAFLD ${ }^{[74,75]}$. Independent of its association with cardiometabolic disease, plasma lipidomic studies in NAFLD and NASH patients have also shown that lipid dysregulation is important in NAFLD pathogenesis, where levels of palmitoleic and oleic acids are increased ${ }^{[76-78]}$. These plasma levels were reflective of an increase in the activity of certain lipid enzymes, such as stearoyl-CoA desaturase 1 (SCD1), the rate limiting enzyme in monounsaturated fatty acids ${ }^{[77,78]}$, which is now being targeted in phase 3 clinical trials for the treatment of NAFLD ${ }^{[76,79,80]}$. Plasma (whole body) and liver lipid compositions also do not always correlate such that understanding lipid dysregulation becomes even more complex ${ }^{[78]}$.

Over the years studies have showed the benefits of statins for patients with cirrhosis. In a retrospective cohort analysis conducted within the VA from 2008-2016 that included 21,921 patients on statins and 51,023 controls without statins, Kaplan et al. ${ }^{[14]}$ demonstrated that for every year of statin exposure, the associated adjusted HR was 0.92 (95\%CI: 0.89-0.94) for mortality. This was seen in all etiologies of cirrhosis including NAFLD and NASH, which comprised $23 \%$ of the cohort. These benefits of statins have also been reported in HCC. In another retrospective cohort within the VA from 2002-2016, Thrift et al. ${ }^{[15]}$ reported that after a diagnosis of HCC, statin users had a decreased risk of cancer-specific death with an adjusted HR of 0.85 (95\%CI: 0.77-0.93). Their sub-group analysis of NAFLD-associated HCCs did not demonstrate a decrease in cancer-specific (adjusted $\mathrm{HR}=1.80,95 \% \mathrm{CI}$ : 0.59-1.08) or all-cause (adjusted HR $=0.90$, 95\%CI: 0.73-1.10) mortalities. The benefits were evident in the group of patients with cirrhosis however, for both cancer-specific (adjusted HR $=0.80,95 \% \mathrm{CI}$ : 0.68-0.94) and all-cause (adjusted $\mathrm{HR}=0.88,95 \% \mathrm{CI}$ : 0.79-0.98) mortalities, respectively, suggesting a fibrosis or cirrhosis-specific effect ${ }^{[15]}$. A nested case-control study conducted from 2002-2013 in the Republic of Korea also demonstrated a benefit from statin use with a reduced risk of HCC development (adjusted OR $=0.44,95 \%$ CI: $0.33-0.58)^{[81]}$. Several meta-analyses have also confirmed these findings across different study populations, health care systems and etiologies of $\mathrm{HCC}^{[82-84]}$. The anti-fibrotic and chemoprotective effects of statins are thought to be potentially independent of their lipid-lowering mechanisms and through other pleiotropic effects mediated by the mevalonate pathway ${ }^{[85,86]}$. Among the statins, those that are lipophilic (atorvastatin and simvastatin) have been linked to reduced HCC incidence and mortality outcomes compared to hydrophilic statins (pravastatin and rosuvastatin) in patients with chronic hepatitis B or C-related $\mathrm{HCC}^{[17]}$. To the best of our knowledge, the differentiating effects of the type of statin used in NAFLD and NAFLD-associated HCC have not been studied.

\section{Aspirin}

Chronic inflammation is a known risk factor for fibrosis. Non-steroidal anti-inflammatory drugs, including aspirin, have been associated with having chemoprotective effects in other malignancies including colorectal, breast, prostate and other gastrointestinal cancers ${ }^{[87,88]}$. Early in vitro studies demonstrated that aspirin had chemoprotective effects against $\mathrm{HCC}^{[89]}$. Sahasrabuddhe et al. ${ }^{[90]}$ assessed the association between aspirin use in a prospectively collected data of 300,504 patients in the National Institutes of Health-AARP Diet and Health Study cohort, where patients had used aspirin over the previous 12 months ( $73 \%$ used aspirin). Of the 250 patients who developed HCC, those on aspirin had decreased risk for both HCC (adjusted relative risk $=0.49$, 
95\%CI: 0.39-0.61) and chronic liver disease mortality (adjusted relative risk $=0.55,95 \%$ CI: $0.45-0.67)^{[91]}$. In an observational study using the Liver Cancer Pooling Project which consisted of US cohorts from the National Cancer Institute Cohort Consortium, of the 679 patients who developed HCC, those who were on aspirin also had a $32 \%$ reduction in the risk of HCC (adjusted HR $=0.68,95 \%$ CI: 0.57-0.81) over the followup period of 11.9 years $^{[92]}$. Although there was no mention of NAFLD patients (mostly hepatitis B and C), this early study demonstrated a potential benefit of aspirin in other cirrhosis populations at risk for HCC. These data led to a more recent study using the Nurses' Health Study and the Health Professionals Followup Study, where over a median follow-up of 8 years, 133,371 patients were assessed for HCC development. Regular users of aspirin ( $\geq 2$ doses; $325 \mathrm{mg}$ per week) had a reduced risk of HCC (adjusted HR = 0.51, 95\%CI: 0.34-0.77), which appeared to be dose and time-dependent ${ }^{[16]}$. Patients who used aspirin for 5 years or more had the lowest risk of HCC development (adjusted HR = 0.41, 95\%CI: 0.21-0.77). Again, the etiology of HCC and cirrhosis was not evident in the study, although one would expect these data to extrapolate to NAFLD-associated HCC $^{[16]}$. This is further supported by NASH animal models treated with aspirin demonstrating a decrease in hepatic fibrosis through decreased activation of pro-inflammatory pathways, potentially by altering the microbiome ${ }^{\left[{ }^{[3]}\right]}$. Further studies will be needed to ascertain this however, especially given the benefit of aspirin in cardiovascular disease, which is one of the leading causes of mortality in that patient population $^{[94]}$.

\section{Microbiome}

Advancements in technology, accessibility to sequencing and manipulation of big data has introduced tools to start understanding how the microbiome contributes to NAFLD, NASH and HCC progression. There is increasing evidence that gut dysbiosis plays a key role in driving the progression of NAFLD to NASH and liver cirrhosis by creating a micro-environment which supports: (1) altered energy absorption ${ }^{[95]}$, (2) modification of gut permeability ${ }^{[96,97]}$, (3) promotion of chronic low-level inflammation ${ }^{[98]}$ and, (4) dysregulation of bile acid signaling ${ }^{[96,99-101]}$. There is however, a limited understanding of the unique relationship between intestinal microbiota, dysbiosis and the development of HCC.

Studies have consistently shown that two phyla of bacteria are dominant within the gut flora, Firmicutes and Bacteroidetes and that their ratios are altered in NAFLD/NASH patients when compared to healthy controls $^{[100,102-105]}$. In a recent study using whole-genome shotgun sequencing of DNA extracted from stool samples, Loomba et al. ${ }^{[106]}$ analyzed the microbiota of subjects with worsening degrees of fibrosis. The authors discovered that in patients with mild/moderate (Fo-F1) fibrosis, the gut flora is dominated by Firmicutes and Bacterioidetes followed by Proteobacteria and Actinobacteria. In contrast, Proteobacteria levels were augmented in patients with severe fibrosis $(\mathrm{F} \geq 2)$ while levels of Firmicutes were diminished. In patients with advanced fibrosis, Bacteroides vulgatus and Escherichia coli (E.coli) were the most abundant organisms. Given that advanced fibrosis is a risk factor for HCC, it is conceivable that similar differences may be found in patients with HCC. Indeed, a study performed by Grat et al. ${ }^{[107]}$ comparing the stool composition of patients with and without HCC (matched by etiology of cirrhosis and MELD scores) discovered that patients with HCC had significantly higher levels of E. coli in their stools.

Studies have also shown that alcohol espouses gut permeability through the alteration of tight junctions in gut epithelium ${ }^{[108]}$. With the liver being a first-pass organ, it is likely that subjects with gut dysbiosis are predisposed to inappropriate translocation of gut bacteria and their endotoxins, leading to a chronic state of inflammation. This is supported by data from Ponziani et al. ${ }^{[109]}$ who showed that compared to patients with NAFLD cirrhosis without HCC, those with HCC have higher levels of fecal calprotectin - a surrogate measure of gastrointestinal inflammation. Furthermore, Ponziani et al ${ }^{[109]}$ demonstrated that independent of HCC, patients with compensated liver cirrhosis have higher levels of plasma lipopolysaccharide (LPS). LPS is a well-known endotoxin that simulates toll-like (TLR) and nod-like receptors in the intestinal epithelium. $\mathrm{NASH}$ patients have been shown to have higher expression of circulating LPS levels as well as localization to 
hepatocytes, which subsequently leads to activation of TLR4 and pro-fibrotic pathways ${ }^{[93]}$. Overexpression of TLRs leads to overproduction of chemokine ligand (CCL) 3, CCL4, CCL5 and interleukin (IL) 4, proinflammatory proteins known to be elevated in the presence of HCC, with IL-8 known specifically to be a hepatocarcinogen $^{[109]}$.

Beyond modification of intestinal microbiota and overstimulation of the host's innate immune system, dysbiosis has also been shown to disrupt bile acid regulation, where under physiological conditions, the microbiome metabolizes primary bile acids to secondary bile acids that are recirculated through the enterohepatic circulation ${ }^{[110]}$. When comparing patients with NAFLD to healthy controls and those with simple steatosis, Mouzaki et al. ${ }^{[100]}$ discovered that NAFLD patients had higher fecal levels of primary bile acids, specifically colic acid, chenodeoxycholic acid and lithocholic acid. Others have also shown, using animal models, that elevated levels of lithocholic acid may be carcinogenic ${ }^{[100,102]}$. Bile acid dysbiosis in patients with cirrhosis is also well illustrated by Jacobs et al. ${ }^{[11]}$ using duodenal aspirate analyses. Although NASH only comprised $13 \%$ of the cohort of patients with cirrhosis, the study identified microbial differences based on the etiology of the cirrhosis, cirrhosis complications (specifically patients with hepatic encephalopathy) and ethnic differences where Hispanics were found to have lower levels of two conjugated forms of ursodeoycholic acid. This is especially interesting given the ethnic differences previously described in Hispanics and the observation that ursodeoycholic acid may have anti-carcinogenic effects on HCC ${ }^{[12-114]}$.

The role of gut dysbiosis in creating a pro-carcinogenic environment is further supported by animal studies. Specifically, in mice models, researchers have shown that the administration of antibiotics/probiotics disrupts the development of new HCC lesions. The replacement of the pro-inflammatory gut milieu, either with sterilization or bacterial replacement, highlights once again the role of the gut-hepatic axis in HCC development, and brings to light the potential role of therapeutics in patients at high risk of HCC ${ }^{[15-117]}$.

Overall, gut dysbiosis has been repeatedly shown to promote metabolic diseases and accelerate the progression of fatty liver disease. There is now increasing evidence however, that the gut microbiome acts as an independent risk factor for HCC development. By promoting an environment that espouses intestinal permeability, hepatic inflammation and bile acid dysregulation, the gut microbiome creates a procarcinogenic environment that may allow for the development of HCC, potentially by working as an epigenetic regulator of gene expression. Most studies in the literature are currently limited to animal models, and of those involving human subjects, samples sizes are often limited by their understandably strict inclusion criteria. Thus, further studies are needed to elucidate the intricate relationship between gut dysbiosis and HCC. Although far from clinical application, this also opens up new avenues for biomarker discovery and potentially, therapies.

\section{CIRRHOSIS VS. NON-CIRRHOSIS}

As highlighted above, work remains to be done to further understand the prevalence, causes and outcomes of NAFLD-associated HCC given its complexities with many environmental contributors. Complicating the presentation of NAFLD-associated HCC is that it can occur in a non-cirrhosis background, which causes a clinical dilemma to providers given the lack of current screening guidelines for this patient population. It is estimated that the prevalence of NASH-associated HCC in patients without cirrhosis to be $38 \%$ based on a recent meta-analysis ${ }^{[11]}$, which differs based on the population, country and how the study was conducted. In Japan, where patients can also have "lean" NAFLD, studies have reported that NASH-related HCC can occur without cirrhosis in $38 \%-49 \%$ of cases ${ }^{[118-120]}$. A multi-center prospective study conducted in Spain reported a prevalence of $50 \%$ of HCC in NAFLD patients without cirrhosis ${ }^{[12]}$. Similarly, a retrospective study in France assessing the prevalence of non-cirrhosis HCC in a cohort of 323 HCCs over a 20 -year span (of which $12 \%$ were due to NAFLD) determined that $63 \%$ of the cases occurred in the absence of bridging fibrosis/cirrhosis, although this was biased towards patients without advanced liver disease who could undergo hepatic 


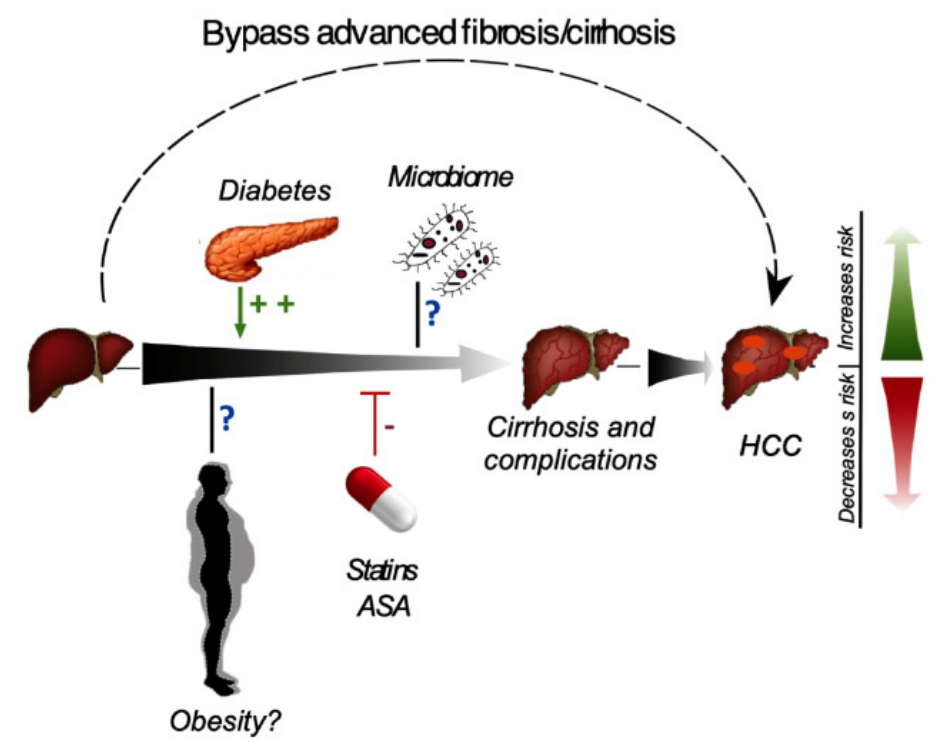

Figure 1. Schematic diagram of the spectrum of NAFLD to NAFLD-associated HCC and the clinical factors implicated in its pathogenesis or prevention. NAFLD: nonalcoholic fatty liver disease; HCC: hepatocellular carcinoma; ASA: aspirin

resection instead of liver transplantation ${ }^{[121]}$.

Interestingly, statin use or dyslipidemia also appears to have different effects on non-cirrhosis HCC patients. For instance, using Taiwan's National Health Insurance Research Database that included 31,751 NAFLD patients from 1998-2012, Lee et al. ${ }^{[13]}$ demonstrated that patients on statin therapy (35\% of all patients) had a decreased risk for HCC (adjusted HR $=0.29,95 \% \mathrm{CI}$ : 0.21-0.68). Few other studies have addressed the effects of statins between the cirrhosis and non-cirrhosis NAFLD patient, which necessitates future work in this area.

Animal studies have shed some light on the pathogenesis of NAFLD and NAFLD-associated HCC. Through a series of detailed experiments, Grohmann et al. ${ }^{[122]}$ demonstrate that while obesity promotes NASH pathogenesis through STAT-1 (signal transducer and activator of transcription 1) activation, NASHassociated HCC is mostly driven by STAT-3 (signal transducer and activator of transcription 3), a transcription factor implicated in the immune system. They further corroborated this using human samples as proof of concept. Their work was complimentary to previous reports showing that STAT-3 activation correlates with tumor aggressiveness and prognosis ${ }^{[123,124]}$. As our knowledge of NAFLD and NAFLD-associated HCC advances, it is becoming evident that the two diseases are divergent and should, potentially, be thought of as separate entities and not on the same spectrum [Figure 1]. This is also apparent in our epidemiological studies where we found that NAFLD-associated HCC tended to occur in non-Hispanic patients, suggesting different mechanisms of action between the cirrhosis and non-cirrhosis patient populations (manuscript submitted).

\section{SCREENING?}

Expert societies recommend HCC screening with bi-annual ultrasounds with or without alpha-fetal protein (AFP) or other biomarkers, based on its cost-effectiveness and benefits ${ }^{[125,126]}$. Although the incidence of NAFLD-associated HCC remains low overall, given the magnitude of MetS and the NAFLD epidemic, NAFLD-HCC cases are expected to increase. Since HCC can also occur in a non-cirrhotic background, future research is imperative in this field to identify at-risk patient populations that would benefit from screening programs, which have largely operated under a "one-size-fits-all" model. Unlike hepatitis C, B and 
alcohol, NAFLD HCC screening has several challenges. Obesity, common in this patient population, has been shown to decrease the effectiveness of ultrasound screening ${ }^{[127-129]}$. The effects of visceral adipose tissue or intrahepatic steatosis in lesions are also unclear. The use of other imaging modalities has been proposed including abbreviated MRI scans, which are promising given their sensitivity and specificity, although their cost-effectiveness remains to be evaluated ${ }^{[130,131]}$.

Over the years, new biomarkers have been introduced including the Lens culinaris lectin-binding subfraction of the AFP (AFP-L 3\%) ${ }^{[132]}$ and des gamma carboxyy prothrombin ${ }^{[133]}$. The clinical utility of these biomarkers in NAFLD-associated HCC patients remains unknown. In our studies, we found that compared to hepatitis B and C, patients with NAFLD-associated HCC were less likely to be AFP producers (AFP $<10 \mathrm{ng} / \mathrm{mL}$ ) (manuscript submitted). Due to the complex nature of NAFLD, the use of a combination of markers will likely be more clinically relevant. This is demonstrated by Best et al.' ${ }^{[134]}$ study using the GALAD (Gender, Age, AFP-L3, and Des-carboxy-prothormbin) score to predict early detection of NAFLD-associated HCC cases in Europe and Japan, including the sub-group of patients without cirrhosis. These results will need to be validated in the US patient population given the heterogeneity of NAFLD across different ethnic groups, especially given the lower performance of the GALAD score in the sub-group of US-American cohort. Risk stratification calculators have been developed to assess the risk of HCC and the utility of HCC screening, including in the NAFLD patient population, however these have focused on the cirrhosis group which is at higher risk of HCC and have not entered clinical practice yet ${ }^{[24]}$.

Clinical practices therefore vary due to the limited data, which has prompted expert societies to provide some guidance in the form of expert opinion ${ }^{[135]}$. In our local liver transplantation institution, we choose to screen patients yearly with an abdominal ultrasound and blood work, especially if they have a diagnosis of $\mathrm{T} 2 \mathrm{D}$.

\section{CONCLUSIONS AND OUTSTANDING QUESTIONS}

NAFLD-associated HCC is on the rise and will continue to create a large economic burden on health care, prompting essential research. Its heterogenous clinical presentation is reflective of its complex traits with important genetic and non-genetic, as well as environmental risk factors. Although a combination of basic, translational and clinical research has shed some light on its distinct presentations, many questions remain unanswered. The lack of consistent clinical definitions to identify NAFLD and NASH patients when using electronic medical records in research over the years has made comparison between studies challenging. This has been recognized in clinical trials where a larger effort has been made on using consistent and reproducible definitions to identify patients and characterize responses to NASH treatment. Bigger public health questions remain unanswered including who to screen and how to use modifiable factors such as statins and aspirin to mitigate the risk of liver disease progression and HCC, where liver transplantation remains scarce and not available to all patients. In the era of precision healthcare and medicine, identifying "at-risk" populations within the larger NAFLD group will be key to tailoring screening and treatment options and will help providers identify patients in need of close monitoring under the care of subspecialists versus primary care. In light of the complex and heterogenous nature of the disease, identifying "at-risk" patients will likely require a combination of clinical characteristics, biomarker discovery and risk-stratification calculators.

\section{DECLARATIONS}

\section{Authors' contributions}

Involved in conception of the study, drafting of the manuscript and critical revision for important intellectual content: Benhammou JN, Hussain SK, El-Kabany M

Conducted the literature review, drafted the section on the microbiome and provided critical revision of the manuscript for intellectual content: Lin J 


\section{Availability of data and materials}

Not applicable.

\section{Financial support and sponsorship}

JNB- AASLD and DDRC Pilot and Feasibility of the National Institutes of Health under award number DKP3041301 and the National Center for Advancing Translational Sciences at UCLA, CTSI Grant ULTR001881.

\section{Conflicts of interest}

All authors declared that there are no conflicts of interest.

\section{Ethical approval and consent to participate}

Not applicable.

\section{Consent for publication}

Not applicable.

\section{Copyright}

(c) The Author(s) 2020.

\section{REFERENCES}

1. Loomba R, Sanyal AJ. The global NAFLD epidemic. Nat Rev Gastroenterol Hepatol 2013;10:686-90.

2. Adams LA, Lindor KD. Nonalcoholic fatty liver disease. Ann Epidemiol 2007;17:863-9.

3. Younossi ZM, Koenig AB, Abdelatif D, Fazel Y, Henry L, et al. Global epidemiology of nonalcoholic fatty liver disease-Meta-analytic assessment of prevalence, incidence, and outcomes. Hepatology 2016;64:73-84.

4. Kleiner DE, Brunt EM, Van Natta M, Behling C, Contos MJ, et al. Design and validation of a histological scoring system for nonalcoholic fatty liver disease. Hepatology 2005;41:1313-21.

5. Page JM, Harrison SA. NASH and HCC. Clin Liver Dis 2009;13:631-47.

6. Sanyal AJ; American Gastroenterological Association. AGA technical review on nonalcoholic fatty liver disease. Gastroenterology 2002;123:1705-25.

7. Estes C, Razavi H, Loomba R, Younossi Z, Sanyal AJ. Modeling the epidemic of nonalcoholic fatty liver disease demonstrates an exponential increase in burden of disease. Hepatology 2018;67:123-33.

8. Allen AM, Van Houten HK, Sangaralingham LR, Talwalkar JA, McCoy RG. Healthcare cost and utilization in nonalcoholic fatty liver disease: real-world data from a large U.S. claims database. Hepatology 2018;68:2230-8.

9. Younossi ZM, Henry L, Bush H, Mishra A. Clinical and economic burden of nonalcoholic fatty liver disease and nonalcoholic steatohepatitis. Clin Liver Dis 2018;22:1-10.

10. Younossi ZM, Zheng L, Stepanova M, Henry L, Venkatesan C, et al. Trends in outpatient resource utilizations and outcomes for Medicare beneficiaries with nonalcoholic fatty liver disease. J Clin Gastroenterol 2015;49:222-7.

11. Stine JG, Wentworth BJ, Zimmet A, Rinella ME, Loomba R, et al. Systematic review with meta-analysis: risk of hepatocellular carcinoma in non-alcoholic steatohepatitis without cirrhosis compared to other liver diseases. Aliment Pharmacol Ther 2018;48:696-703.

12. Piscaglia F, Svegliati-Baroni G, Barchetti A, Pecorelli A, Marinelli S, et al. Clinical patterns of hepatocellular carcinoma in nonalcoholic fatty liver disease: a multicenter prospective study. Hepatology 2016;63:827-38.

13. Lee TY, Wu JC, Yu SH, Lin JT, Wu MS, et al. The occurrence of hepatocellular carcinoma in different risk stratifications of clinically noncirrhotic nonalcoholic fatty liver disease. Int J Cancer 2017;141:1307-14.

14. Kaplan DE, Serper MA, Mehta R, Fox R, John B, et al. Effects of hypercholesterolemia and statin exposure on survival in a large national cohort of patients with cirrhosis. Gastroenterology 2019;156:1693-706.e12.

15. Thrift AP, Natarajan Y, Liu Y, El-Serag HB. Statin use after diagnosis of hepatocellular carcinoma is associated with decreased mortality. Clin Gastroenterol Hepatol 2019;17:2117-25.e3.

16. Simon TG, Ma Y, Ludvigsson JF, Chong DQ, Giovannucci EL, et al. Association between aspirin use and risk of hepatocellular carcinoma. JAMA Oncol 2018;4:1683-90.

17. Simon TG, Duberg AS, Aleman S, Hagstrom H, Nguyen LH, et al. Lipophilic statins and risk for hepatocellular carcinoma and death in patients with chronic viral hepatitis: results from a nationwide Swedish population. Ann Intern Med 2019;171:318-27.

18. Anstee QM, Reeves HL, Kotsiliti E, Govaere O, Heikenwalder M. From NASH to HCC: current concepts and future challenges. Nat Rev Gastroenterol Hepatol 2019;16:411-28.

19. Singal AG, El-Serag HB. Hepatocellular carcinoma from epidemiology to prevention: translating knowledge into practice. Clin Gastroenterol Hepatol 2015;13:2140-51. 
20. Siegel RL, Miller KD, Jemal A. Cancer statistics, 2017. CA Cancer J Clin 2017;67:7-30.

21. Welzel TM, Graubard BI, Quraishi S, Zeuzem S, Davila JA, et al. Population-attributable fractions of risk factors for hepatocellular carcinoma in the United States. Am J Gastroenterol 2013;108:1314-21.

22. Kanwal F, Kramer JR, Mapakshi S, Natarajan Y, Chayanupatkul M, et al. Risk of hepatocellular cancer in patients with non-alcoholic fatty liver disease. Gastroenterology 2018;155:1828-37.e2.

23. Mittal S, Sada YH, El-Serag HB, Kanwal F, Duan Z, et al. Temporal trends of nonalcoholic fatty liver disease-related hepatocellular carcinoma in the veteran affairs population. Clin Gastroenterol Hepatol 2015;13:594-601.e1.

24. Ioannou GN, Green P, Kerr KF, Berry K. Models estimating risk of hepatocellular carcinoma in patients with alcohol or NAFLD-related cirrhosis for risk stratification. J Hepatol 2019;71:523-33.

25. Younossi Z, Stepanova M, Ong JP, Jacobson IM, Bugianesi E, et al. Nonalcoholic steatohepatitis is the fastest growing cause of hepatocellular carcinoma in liver transplant candidates. Clin Gastroenterol Hepatol 2019;17:748-55.e3.

26. Wong RJ, Cheung R, Ahmed A. Nonalcoholic steatohepatitis is the most rapidly growing indication for liver transplantation in patients with hepatocellular carcinoma in the U.S. Hepatology 2014;59:2188-95.

27. Wong RJ, Aguilar M, Cheung R, Perumpail RB, Harrison SA, et al. Nonalcoholic steatohepatitis is the second leading etiology of liver disease among adults awaiting liver transplantation in the United States. Gastroenterology 2015;148:547-55.

28. Petrick JL, Braunlin M, Laversanne M, Valery PC, Bray F, et al. International trends in liver cancer incidence, overall and by histologic subtype, 1978-2007. Int J Cancer 2016;139:1534-45.

29. Kawamura Y, Arase Y, Ikeda K, Seko Y, Imai N, et al. Large-scale long-term follow-up study of Japanese patients with non-alcoholic Fatty liver disease for the onset of hepatocellular carcinoma. Am J Gastroenterol 2012;107:253-61.

30. Alexander M, Loomis AK, van der Lei J, Duarte-Salles T, Prieto-Alhambra D, et al. Risks and clinical predictors of cirrhosis and hepatocellular carcinoma diagnoses in adults with diagnosed NAFLD: real-world study of 18 million patients in four European cohorts. BMC Med 2019;17:95.

31. Haldar D, Kern B, Hodson J, Armstrong MJ, Adam R, et al. Outcomes of liver transplantation for non-alcoholic steatohepatitis: a European Liver Transplant Registry study. J Hepatol 2019;71:313-22.

32. Fan JG, Kim SU, Wong VW. New trends on obesity and NAFLD in Asia. J Hepatol 2017;67:862-73.

33. Wong MCS, Huang JLW, George J, Huang J, Leung C, et al. The changing epidemiology of liver diseases in the Asia-Pacific region. Nat Rev Gastroenterol Hepatol 2019;16:57-73.

34. Cho EJ, Kwack MS, Jang ES, You SJ, Lee JH, et al. Relative etiological role of prior hepatitis B virus infection and nonalcoholic fatty liver disease in the development of non-B non-C hepatocellular carcinoma in a hepatitis B-endemic area. Digestion 2011;84:17-22.

35. Hagström H, Nasr P, Ekstedt M, Hammar U, Stål P, et al. Risk for development of severe liver disease in lean patients with nonalcoholic fatty liver disease: a long-term follow-up study. Hepatol Commun 2018;2:48-57.

36. Browning JD, Szczepaniak LS, Dobbins R, Nuremberg P, Horton JD, et al. Prevalence of hepatic steatosis in an urban population in the United States: impact of ethnicity. Hepatology 2004;40:1387-95.

37. Caldwell SH, Harris DM, Patrie JT, Hespenheide EE. Is NASH underdiagnosed among African Americans? Am J Gastroenterol 2002;97:1496-500.

38. Browning JD, Kumar KS, Saboorian MH, Thiele DL. Ethnic differences in the prevalence of cryptogenic cirrhosis. Am J Gastroenterol 2004;99:292-8.

39. Schwimmer JB, Celedon MA, Lavine JE, Salem R, Campbell N, et al. Heritability of nonalcoholic fatty liver disease. Gastroenterology 2009; 136:1585-92.

40. Loomba R, Schork N, Chen CH, Bettencourt R, Bhatt A, et al. Heritability of hepatic fibrosis and steatosis based on a prospective twin study. Gastroenterology 2015;149:1784-93.

41. Romeo S, Kozlitina J, Xing C, Pertsemlidis A, Cox D, et al. Genetic variation in PNPLA3 confers susceptibility to nonalcoholic fatty liver disease. Nat Genet 2008;40:1461-5.

42. Dongiovanni P, Donati B, Fares R, Lombardi R, Mancina RM, et al. PNPLA3 I148M polymorphism and progressive liver disease. World J Gastroenterol 2013;19:6969-78.

43. Smagris E, BasuRay S, Li J, Huang Y, Lai KM, et al. Pnpla3I148M knockin mice accumulate PNPLA3 on lipid droplets and develop hepatic steatosis. Hepatology 2015;61:108-18.

44. Sookoian S, Pirola CJ. Meta-analysis of the influence of I148M variant of patatin-like phospholipase domain containing 3 gene (PNPLA3) on the susceptibility and histological severity of nonalcoholic fatty liver disease. Hepatology 2011;53:1883-94.

45. Liu YL, Patman GL, Leathart JB, Piguet AC, Burt AD, et al. Carriage of the PNPLA3 rs $738409 \mathrm{C}>\mathrm{G}$ polymorphism confers an increased risk of non-alcoholic fatty liver disease associated hepatocellular carcinoma. J Hepatol 2014;61:75-81.

46. Kozlitina J, Smagris E, Stender S, Nordestgaard BG, Zhou HH, et al. Exome-wide association study identifies a TM6SF2 variant that confers susceptibility to nonalcoholic fatty liver disease. Nat Genet 2014;46:352-6.

47. Falleti E, Cussigh A, Cmet S, Fabris C, Toniutto P. PNPLA3 rs738409 and TM6SF2 rs58542926 variants increase the risk of hepatocellular carcinoma in alcoholic cirrhosis. Dig Liver Dis 2016;48:69-75.

48. Mancina RM, Dongiovanni P, Petta S, Pingitore P, Meroni M, et al. The MBOAT7-TMC4 variant rs641738 increases risk of nonalcoholic fatty liver disease in individuals of european descent. Gastroenterology 2016;150:1219-30.e6.

49. Luukkonen PK, Zhou Y, Hyötyläinen T, Leivonen M, Arola J, et al. The MBOAT7 variant rs641738 alters hepatic phosphatidylinositols and increases severity of non-alcoholic fatty liver disease in humans. J Hepatol 2016;65:1263-5.

50. Donati B, Dongiovanni P, Romeo S, Meroni M, McCain M, et al. MBOAT7 rs641738 variant and hepatocellular carcinoma in non- 
cirrhotic individuals. Sci Rep 2017;7:4492.

51. Pelusi S, Baselli G, Pietrelli A, Dongiovanni P, Donati B, et al. Rare pathogenic variants predispose to hepatocellular carcinoma in nonalcoholic fatty liver disease. Sci Rep 2019;9:3682.

52. El-Serag HB, Lau M, Eschbach K, Davila J, Goodwin J. Epidemiology of hepatocellular carcinoma in Hispanics in the United States. Arch Intern Med 2007;167:1983-9.

53. Rich NE, Hester C, Odewole M, Murphy CC, Parikh ND, et al. Racial and ethnic differences in presentation and outcomes of hepatocellular carcinoma. Clin Gastroenterol Hepatol 2019;17:551-9.e1.

54. Garske KM, Pan DZ, Miao Z, Bhagat YV, Comenho C, et al. Reverse gene-environment interaction approach to identify variants influencing body-mass index in humans. Nat Metab 2019;1:630-42.

55. Benhammou JN, Ko A, Alvarez M, Kaikkonen MU, Rankin C, et al. Novel lipid long intervening noncoding RNA, oligodendrocyte maturation-associated long intergenic noncoding RNA, regulates the liver steatosis gene stearoyl-coenzyme a desaturase as an enhancer RNA. Hepatol Commun 2019;3:1356-72.

56. Villanueva A, Portela A, Sayols S, Battiston C, Hoshida Y, et al. DNA methylation-based prognosis and epidrivers in hepatocellular carcinoma. Hepatology 2015;61:1945-56.

57. Fei Q, Shang K, Zhang J, Chuai S, Kong D, et al. Histone methyltransferase SETDB1 regulates liver cancer cell growth through methylation of p53. Nat Commun 2015;6:8651.

58. Xu RH, Wei W, Krawczyk M, Wang W, Luo H, et al. Circulating tumour DNA methylation markers for diagnosis and prognosis of hepatocellular carcinoma. Nat Mater 2017;16:1155-61.

59. Ng CKY, Di Costanzo GG, Terracciano LM, Piscuoglio S. Circulating cell-free DNA in hepatocellular carcinoma: current insights and outlook. Front Med (Lausanne) 2018;5:78.

60. El-Serag HB, Tran T, Everhart JE. Diabetes increases the risk of chronic liver disease and hepatocellular carcinoma. Gastroenterology 2004; $126: 460-8$.

61. Lai SW, Chen PC, Liao KF, Muo CH, Lin CC, et al. Risk of hepatocellular carcinoma in diabetic patients and risk reduction associated with anti-diabetic therapy: a population-based cohort study. Am J Gastroenterol 2012;107:46-52.

62. Chen HF, Chen P, Li CY. Risk of malignant neoplasms of liver and biliary tract in diabetic patients with different age and sex stratifications. Hepatology 2010;52:155-63.

63. Simon TG, King LY, Chong DQ, Nguyen LH, Ma Y, et al. Diabetes, metabolic comorbidities, and risk of hepatocellular carcinoma: results from two prospective cohort studies. Hepatology 2018;67:1797-806.

64. Cancer Prevention Study II. The American Cancer Society Prospective Study. Stat Bull Metrop Insur Co 1992;73:21-9.

65. Karagozian R, Derdak Z, Baffy G. Obesity-associated mechanisms of hepatocarcinogenesis. Metabolism 2014;63:607-17.

66. Ioannou GN, Weiss NS, Boyko EJ, Kowdley KV, Kahn SE, et al. Is central obesity associated with cirrhosis-related death or hospitalization? A population-based, cohort study. Clin Gastroenterol Hepatol 2005;3:67-74.

67. Schlesinger S, Aleksandrova K, Pischon T, Fedirko V, Jenab M, et al. Abdominal obesity, weight gain during adulthood and risk of liver and biliary tract cancer in a European cohort. Int J Cancer 2013;132:645-57.

68. Pang Q, Zhang JY, Song SD, Qu K, Xu XS, et al. Central obesity and nonalcoholic fatty liver disease risk after adjusting for body mass index. World J Gastroenterol 2015;21:1650-62.

69. Consultation WE. Appropriate body-mass index for Asian populations and its implications for policy and intervention strategies. Lancet 2004;363:157-63.

70. Welzel TM, Graubard BI, Zeuzem S, El-Serag HB, Davila JA, et al. Metabolic syndrome increases the risk of primary liver cancer in the United States: a study in the SEER-Medicare database. Hepatology 2011;54:463-71.

71. Borena W, Strohmaier S, Lukanova A, Bjørge T, Lindkvist B, et al. Metabolic risk factors and primary liver cancer in a prospective study of 578,700 adults. Int J Cancer 2012;131:193-200.

72. Chiang CH, Lee LT, Hung SH, Lin WY, Hung HF, et al. Opposite association between diabetes, dyslipidemia, and hepatocellular carcinoma mortality in the middle-aged and elderly. Hepatology 2014;59:2207-15.

73. Chalasani N. Statins and hepatotoxicity: focus on patients with fatty liver. Hepatology 2005;41:690-5.

74. Chalasani N, Younossi Z, Lavine JE, Diehl AM, Brunt EM, et al. The diagnosis and management of non-alcoholic fatty liver disease: practice guideline by the American Gastroenterological Association, American Association for the Study of Liver Diseases, and American College of Gastroenterology. Gastroenterology 2012;142:1592-609.

75. Bays H, Cohen DE, Chalasani N, Harrison SA, The national lipid association's Statin safety task F. An assessment by the Statin Liver Safety Task Force: 2014 update. J Clin Lipidol 2014;8:S47-57.

76. Puri P, Wiest MM, Cheung O, Mirshahi F, Sargeant C, et al. The plasma lipidomic signature of nonalcoholic steatohepatitis. Hepatology 2009;50:1827-38

77. Chiappini F, Coilly A, Kadar H, Gual P, Tran A, et al. Metabolism dysregulation induces a specific lipid signature of nonalcoholic steatohepatitis in patients. Sci Rep 2017;7:46658.

78. Walle P, Takkunen M, Männistö V, Vaittinen M, Lankinen M, et al. Fatty acid metabolism is altered in non-alcoholic steatohepatitis independent of obesity. Metabolism 2016;65:655-66.

79. Safadi R, Konikoff FM, Mahamid M, Zelber-Sagi S, Halpern M, et al. The fatty acid-bile acid conjugate Aramchol reduces liver fat content in patients with nonalcoholic fatty liver disease. Clin Gastroenterol Hepatol 2014;12:2085-91.e1.

80. Ajmera VH, Cachay E, Ramers C, Vodkin I, Bassirian S, et al. MRI assessment of treatment response in HIV-associated NAFLD: a randomized trial of a stearoyl-coenzyme-A-desaturase-1 inhibitor (ARRIVE Trial). Hepatology 2019;70:1531-45. 
81. Kim G, Jang SY, Nam CM, Kang ES. Statin use and the risk of hepatocellular carcinoma in patients at high risk: a nationwide nested case-control study. J Hepatol 2018;68:476-84.

82. Friedman GD, Achacoso N, Fireman B, Habel LA. Statins and reduced risk of liver cancer: evidence for confounding. J Natl Cancer Inst 2016;108.

83. Yi C, Song Z, Wan M, Chen Y, Cheng X. Statins intake and risk of liver cancer: a dose-response meta analysis of prospective cohort studies. Medicine (Baltimore) 2017;96:e7435.

84. Shi M, Zheng H, Nie B, Gong W, Cui X. Statin use and risk of liver cancer: an update meta-analysis. BMJ Open 2014;4:e005399.

85. Ogura S, Yoshida Y, Kurahashi T, Egawa M, Furuta K, et al. Targeting the mevalonate pathway is a novel therapeutic approach to inhibit oncogenic FoxM1 transcription factor in human hepatocellular carcinoma. Oncotarget 2018;9:21022-35.

86. Gruenbacher G, Thurnher M. Mevalonate metabolism governs cancer immune surveillance. Oncoimmunology 2017;6:e1342917.

87. Cuzick J, Otto F, Baron JA, Brown PH, Burn J, et al. Aspirin and non-steroidal anti-inflammatory drugs for cancer prevention: an international consensus statement. Lancet Oncol 2009;10:501-7.

88. Bosetti C, Gallus S, La Vecchia C. Aspirin and cancer risk: a summary review to 2007. Recent Results Cancer Res 2009;181:231-51.

89. Leng J, Han C, Demetris AJ, Michalopoulos GK, Wu T. Cyclooxygenase-2 promotes hepatocellular carcinoma cell growth through Akt activation: evidence for Akt inhibition in celecoxib-induced apoptosis. Hepatology 2003;38:756-68

90. Sahasrabuddhe VV, Gunja MZ, Graubard BI, Trabert B, Schwartz LM, et al. Nonsteroidal anti-inflammatory drug use, chronic liver disease, and hepatocellular carcinoma. J Natl Cancer Inst 2012;104:1808-14.

91. Schatzkin A, Subar AF, Thompson FE, Harlan LC, Tangrea J, et al. Design and serendipity in establishing a large cohort with wide dietary intake distributions : the National Institutes of Health-American Association of Retired Persons Diet and Health Study. Am J Epidemiol 2001;154:1119-25

92. Petrick JL, Sahasrabuddhe VV, Chan AT, Alavanja MC, Beane-Freeman LE, et al. NSAID use and risk of hepatocellular carcinoma and intrahepatic cholangiocarcinoma: the liver cancer pooling project. Cancer Prev Res (Phila) 2015;8:1156-62.

93. Carpino G, Del Ben M, Pastori D, Carnevale R, Baratta F, et al. Increased liver localization of lipopolysaccharides in human and experimental non-alcoholic fatty liver disease. Hepatology 2019; Epub ahead of print. doi: 10.1002/hep.31056.

94. Paik JM, Henry L, De Avila L, Younossi E, Racila A, et al. Mortality related to nonalcoholic fatty liver disease is increasing in the United States. Hepatol Commun 2019;3:1459-71.

95. Gill SR, Pop M, Deboy RT, Eckburg PB, Turnbaugh PJ, et al. Metagenomic analysis of the human distal gut microbiome. Science 2006;312:1355-9.

96. Miele L, Valenza V, La Torre G, Montalto M, Cammarota G, et al. Increased intestinal permeability and tight junction alterations in nonalcoholic fatty liver disease. Hepatology 2009;49:1877-87.

97. Volynets V, Küper MA, Strahl S, Maier IB, Spruss A, et al. Nutrition, intestinal permeability, and blood ethanol levels are altered in patients with nonalcoholic fatty liver disease (NAFLD). Dig Dis Sci 2012;57:1932-41.

98. Noverr MC, Huffnagle GB. Does the microbiota regulate immune responses outside the gut? Trends Microbiol 2004;12:562-8.

99. Buzzetti E, Pinzani M, Tsochatzis EA. The multiple-hit pathogenesis of non-alcoholic fatty liver disease (NAFLD). Metabolism 2016;65:1038-48.

100. Mouzaki M, Wang AY, Bandsma R, Comelli EM, Arendt BM, et al. Bile acids and dysbiosis in non-alcoholic fatty liver disease. PLoS One 2016;11:e0151829.

101. Henao-Mejia J, Elinav E, Jin C, Hao L, Mehal WZ, et al. Inflammasome-mediated dysbiosis regulates progression of NAFLD and obesity. Nature 2012;482:179-85.

102. Boursier J, Diehl AM. Implication of gut microbiota in nonalcoholic fatty liver disease. PLoS Pathog 2015;11:e1004559.

103. Zhu L, Baker SS, Gill C, Liu W, Alkhouri R, et al. Characterization of gut microbiomes in nonalcoholic steatohepatitis (NASH) patients: a connection between endogenous alcohol and NASH. Hepatology 2013;57:601-9.

104. Ley RE, Turnbaugh PJ, Klein S, Gordon JI. Microbial ecology: human gut microbes associated with obesity. Nature 2006;444:1022-3.

105. Boursier J, Mueller O, Barret M, Machado M, Fizanne L, et al. The severity of nonalcoholic fatty liver disease is associated with gut dysbiosis and shift in the metabolic function of the gut microbiota. Hepatology 2016;63:764-75.

106. Loomba R, Seguritan V, Li W, Long T, Klitgord N, et al. Gut microbiome-based metagenomic signature for non-invasive detection of advanced fibrosis in human nonalcoholic fatty liver disease. Cell Metab 2019;30:607.

107. Grąt M, Wronka KM, Krasnodębski M, Masior L, Lewandowski Z, et al. Profile of gut microbiota associated with the presence of hepatocellular cancer in patients with liver cirrhosis. Transplant Proc 2016;48:1687-91.

108. Chassaing B, Etienne-Mesmin L, Gewirtz AT. Microbiota-liver axis in hepatic disease. Hepatology 2014;59:328-39.

109. Ponziani FR, Bhoori S, Castelli C, Putignani L, Rivoltini L, et al. Hepatocellular carcinoma is associated with gut microbiota profile and inflammation in nonalcoholic fatty liver disease. Hepatology 2019;69:107-20.

110. Roberts MS, Magnusson BM, Burczynski FJ, Weiss M. Enterohepatic circulation: physiological, pharmacokinetic and clinical implications. Clin Pharmacokinet 2002;41:751-90.

111. Jacobs JP, Dong TS, Agopian V, Lagishetty V, Sundaram V, et al. Microbiome and bile acid profiles in duodenal aspirates from patients with liver cirrhosis: the Microbiome, Microbial Markers and Liver Disease Study. Hepatol Res 2018;48:1108-17.

112. Chung GE, Yoon JH, Lee JH, Kim HY, Myung SJ, et al. Ursodeoxycholic acid-induced inhibition of DLC1 protein degradation leads to suppression of hepatocellular carcinoma cell growth. Oncol Rep 2011;25:1739-46.

113. Liu H, Xu HW, Zhang YZ, Huang Y, Han GQ, et al. Ursodeoxycholic acid induces apoptosis in hepatocellular carcinoma xenografts in mice. World J Gastroenterol 2015;21:10367-74. 
114. Zhu L, Shan LJ, Liu YJ, Chen D, Xiao XG, et al. Ursodeoxycholic acid induces apoptosis of hepatocellular carcinoma cells in vitro. J Dig Dis 2014;15:684-93.

115. Li J, Sung CY, Lee N, Ni Y, Pihlajamäki J, et al. Probiotics modulated gut microbiota suppresses hepatocellular carcinoma growth in mice. Proc Natl Acad Sci U S A 2016;113:E1306-15.

116. Zhang HL, Yu LX, Yang W, Tang L, Lin Y, et al. Profound impact of gut homeostasis on chemically-induced pro-tumorigenic inflammation and hepatocarcinogenesis in rats. J Hepatol 2012;57:803-12.

117. Yoshimoto S, Loo TM, Atarashi K, Kanda H, Sato S, et al. Obesity-induced gut microbial metabolite promotes liver cancer through senescence secretome. Nature 2013;499:97-101.

118. Tokushige K, Hashimoto E, Horie Y, Taniai M, Higuchi S. Hepatocellular carcinoma in Japanese patients with nonalcoholic fatty liver disease, alcoholic liver disease, and chronic liver disease of unknown etiology: report of the nationwide survey. J Gastroenterol 2011;46:1230-7.

119. Yasui K, Hashimoto E, Komorizono Y, Koike K, Arii S, et al. Characteristics of patients with nonalcoholic steatohepatitis who develop hepatocellular carcinoma. Clin Gastroenterol Hepatol 2011;9:428-33.

120. Kawada N, Imanaka K, Kawaguchi T, Tamai C, Ishihara R, et al. Hepatocellular carcinoma arising from non-cirrhotic nonalcoholic steatohepatitis. J Gastroenterol 2009;44:1190-4.

121. Pais R, Fartoux L, Goumard C, Scatton O, Wendum D, et al. Temporal trends, clinical patterns and outcomes of NAFLD-related HCC in patients undergoing liver resection over a 20-year period. Aliment Pharmacol Ther 2017;46:856-63.

122. Grohmann M, Wiede F, Dodd GT, Gurzov EN, Ooi GJ, et al. Obesity drives STAT-1-dependent NASH and STAT-3-dependent HCC. Cell 2018;175:1289-306.e20.

123. Calvisi DF, Ladu S, Gorden A, Farina M, Conner EA, et al. Ubiquitous activation of Ras and Jak/Stat pathways in human HCC. Gastroenterology 2006;130:1117-28.

124. He G, Yu GY, Temkin V, Ogata H, Kuntzen C, et al. Hepatocyte IKKbeta/NF-kappaB inhibits tumor promotion and progression by preventing oxidative stress-driven STAT3 activation. Cancer Cell 2010;17:286-97.

125. Marrero JA, Kulik LM, Sirlin CB, Zhu AX, Finn RS, et al. Diagnosis, staging, and management of hepatocellular carcinoma: 2018 practice guidance by the American Association for the Study of Liver Diseases. Hepatology 2018;68:723-50.

126. European Association for the Study of the Liver. Corrigendum to "EASL Clinical Practice Guidelines: Management of hepatocellular carcinoma" [J Hepatol 69 (2018) 182-236]. J Hepatol 2019;70:817.

127. Del Poggio P, Olmi S, Ciccarese F, Di Marco M, Rapaccini GL, et al. Factors that affect efficacy of ultrasound surveillance for early stage hepatocellular carcinoma in patients with cirrhosis. Clin Gastroenterol Hepatol 2014;12:1927-33.e2.

128. Simmons O, Fetzer DT, Yokoo T, Marrero JA, Yopp A, et al. Predictors of adequate ultrasound quality for hepatocellular carcinoma surveillance in patients with cirrhosis. Aliment Pharmacol Ther 2017;45:169-77.

129. Simmons O, Fetzer DT, Yokoo T, Marrero JA, Yopp A, et al. Editorial: ultrasound surveillance of hepatocellular carcinoma in the $21 \mathrm{st}$ century - authors' reply. Aliment Pharmacol Ther 2017;45:562-63.

130. Zhang E, Wartelle-Bladou C, Lepanto L, Lachaine J, Cloutier G, et al. Cost-utility analysis of nonalcoholic steatohepatitis screening. Eur Radiol 2015;25:3282-94.

131. Khatri G, Pedrosa I, Ananthakrishnan L, de Leon AD, Fetzer DT, et al. Abbreviated-protocol screening MRI vs. complete-protocol diagnostic MRI for detection of hepatocellular carcinoma in patients with cirrhosis: an equivalence study using LI-RADS v2018. J Magn Reson Imaging 2020;51:415-25.

132. Leerapun A, Suravarapu SV, Bida JP, Clark RJ, Sanders EL, et al. The utility of Lens culinaris agglutinin-reactive alpha-fetoprotein in the diagnosis of hepatocellular carcinoma: evaluation in a United States referral population. Clin Gastroenterol Hepatol 2007;5:394-402.

133. Liebman HA, Furie BC, Tong MJ, Blanchard RA, Lo KJ, et al. Des-gamma-carboxy (abnormal) prothrombin as a serum marker of primary hepatocellular carcinoma. N Engl J Med 1984;310:1427-31.

134. Best J, Bechmann LP, Sowa JP, Sydor S, Dechêne A, et al. GALAD score detects early hepatocellular carcinoma in an international cohort of patients with nonalcoholic steatohepatitis. Clin Gastroenterol Hepatol 2020;18:728-35.e4.

135. Loomba R, Lim JK, Patton H, El-Serag HB. AGA clinical practice update on screening and surveillance for hepatocellular carcinoma in patients with nonalcoholic fatty liver disease: expert review. Gastroenterology 2020;158:1822-30.

136. Younossi ZM, Otgonsuren M, Henry L, Venkatesan C, Mishra A, et al. Association of nonalcoholic fatty liver disease (NAFLD) with hepatocellular carcinoma (HCC) in the United States from 2004 to 2009. Hepatology 2015;62:1723-30.

137. Dyson J, Jaques B, Chattopadyhay D, Lochan R, Graham J, et al. Hepatocellular cancer: the impact of obesity, type 2 diabetes and a multidisciplinary team. J Hepatol 2014;60:110-7.

138. Arase Y, Kobayashi M, Suzuki F, Suzuki Y, Kawamura Y, et al. Difference in malignancies of chronic liver disease due to non-alcoholic fatty liver disease or hepatitis C in Japanese elderly patients. Hepatol Res 2012;42:264-72.

139. Shen JH, Li YL, Li D, Wang NN, Jing L, et al. The rs 738409 (I148M) variant of the PNPLA3 gene and cirrhosis: a meta-analysis. J Lipid Res 2015;56:167-75.

140. Vespasiani-Gentilucci U, Gallo P, Dell'Unto C, Volpentesta M, Antonelli-Incalzi R, et al. Promoting genetics in non-alcoholic fatty liver disease: combined risk score through polymorphisms and clinical variables. World J Gastroenterol 2018;24:4835-45. 